\title{
Immunoexpression of Macroh2a in Uveal Melanoma
}

\author{
Lucia Salvatorelli ${ }^{1, *}$, Lidia Puzzo ${ }^{1}$, Giovanni Bartoloni ${ }^{2}$, Stefano Palmucci ${ }^{3}{ }^{\mathbb{C}}$, Antonio Longo ${ }^{4}$, \\ Andrea Russo ${ }^{4}$, Michele Reibaldi ${ }^{4}$, Manlio Vinciguerra ${ }^{5}\left(\mathbb{D}\right.$, Giovanni Li Volti ${ }^{6}(\mathbb{D}$ and \\ Rosario Caltabiano ${ }^{1}$
}

1 Department of Medical and Surgical Sciences and Advanced Technologies, G.F. Ingrassia, Azienda Ospedaliero-Universitaria "Policlinico-Vittorio Emanuele", Anatomic Pathology Section, School of Medicine, University of Catania, 95123 Catania, Italy

2 Pathology Department, University of Catania, 95123 Catania, Italy

3 Department of Medical Surgical Sciences and Advanced Technologies-Radiology I Unit, University Hospital “Policlinico-Vittorio Emanuele”, 95123 Catania, Italy

4 Department of Ophthalmology, University of Catania, 95123 Catania, Italy

5 International Clinical Research Center, St. Anne's University Hospital, 65691 Brno, Czech Republic

6 Department of Biomedical and Biotechnological Sciences, University of Catania, 95123 Catania, Italy

* Correspondence: lucia.salvatorelli@unict.it; Tel.: +39-095-3782138

Received: 26 June 2019; Accepted: 6 August 2019; Published: 8 August 2019

\begin{abstract}
MacroH} 2 \mathrm{~A}$ is a histone variant whose expression has been studied in several neoplasms, including cutaneous melanomas (CMs). In the literature, it has been demonstrated that macroH2A.1 levels gradually decrease during CM progression, and a high expression of macroH2A.1 in CM cells relates to a better prognosis. Although both uveal and cutaneous melanomas arise from melanocytes, uveal melanoma (UM) is biologically and genetically distinct from the more common cutaneous melanoma. Metastasis to the liver is a frequent occurrence in UM, and about $40 \%-50 \%$ of patients die of metastatic disease, even with early diagnosis, proper treatment, and close follow-up. We wanted to investigate macroH2A.1 immunohistochemical expression in UM. Our results demonstrated that mH2A.1 expression was higher in metastatic UM $(21 / 23,91.4 \%)$, while only $18 / 32(56.3 \%)$. UMs without metastases showed mH2A.1 staining. These data could suggest a possible prognostic role for mH2A.1 and could form a basis for developing new pharmacological strategies for UM treatment.
\end{abstract}

Keywords: immunohistochemistry; macroH2A; prognostic factor; uveal melanoma; metastasis

\section{Introduction}

Uveal melanoma (UM) is the most frequent primitive intraocular neoplasm in middle age [1]: it occurs mainly in the choroid and ciliary bodies and less frequently in the iris, and some authors have suggested that these melanomas arise from previous benign nevi [2]. Histologically, three forms of UMs can be identified: (a) the spindle cell variant; (b) the epithelioid cell variant; and (c) the mixed cell variant, showing both epithelioid and spindle cells [3]. The prognosis of UM is poor because about $50 \%$ of patients will develop hepatic metastasis even 10-15 years after surgery [4]. Because of the strange behavior of this tumor, researchers have tried to determine what could be the mechanisms underlying the late development of liver metastases. Histone variants are chromatin components that replace replication-coupled histones in a fraction of nucleosomes and confer unique biological functions to chromatin [5]. MacroH2A (mH2A) is a histone variant whose expression has been studied in cutaneous melanomas (CMs). It has been shown that the loss of $\mathrm{mH} 2 \mathrm{~A}$ isoforms in cutaneous melanomas is correlated with increasing malignant phenotypes: this mechanism would seem to be mediated by the upregulation of CDK8, which inhibits the proliferation of melanoma cells. During CM progression, 
tumor cells show a low expression of $\mathrm{mH} 2 \mathrm{~A}$, and conversely, high levels of $\mathrm{mH} 2 \mathrm{~A}$ expression correlate with a better prognosis [6,7].

In the present study, we studied the immunohistochemical expression of mH2A.1 in 55 primitive UMs, both with and without metastases, to understand whether expression may be correlated with a greater risk of metastasis in order to identify a marker able to predict the behavior of UM.

\section{Materials and Methods}

\subsection{Patients and Tissue Samples}

A retrospective study was performed on 55 primitive choroid and/or ciliary body melanomas after surgical treatment consisting of enucleation in cases not eligible for radiotherapy, such as plaque brachytherapy or proton beam radiotherapy [8], at the Eye Clinic, University of Catania, from October 2009 to October 2017.

No written informed consent was necessary because of the retrospective nature of the study.

The research protocols were conformed to the ethical guidelines of the Declaration of Helsinki.

The patients were 28 males and 27 females at an average age of 67 years (range 29-85). In particular, the patients with metastatic UM were 11 males and 12 females at an average age of 72 years (range 50-85): disease progression caused death in 13 of the 23 patients. The patients with nonmetastatic UM were 17 males and 15 females at an average age of 64 years (range 29-84) (Tables 1 and 2).

Table 1. Demographics, tumor parameters, disease-free time, follow-up, and macroH2A expression in primary uveal melanomas (UMs) without metastasis $(n=32)$.

\begin{tabular}{|c|c|c|c|c|c|c|c|c|c|c|c|c|}
\hline \multirow{2}{*}{ Sex } & \multirow{2}{*}{$\begin{array}{c}\text { Age } \\
\text { (years) }\end{array}$} & \multirow{2}{*}{ Location } & \multirow{2}{*}{$\begin{array}{l}\text { Thickness } \\
\text { (mm) }\end{array}$} & \multirow{2}{*}{$\begin{array}{c}\text { Largest } \\
\text { Diameter } \\
(\mathrm{mm})\end{array}$} & \multirow{2}{*}{$\begin{array}{l}\text { Cell } \\
\text { Type }\end{array}$} & \multirow{2}{*}{$\begin{array}{c}\text { Pathological } \\
\text { T Stage }\end{array}$} & \multirow{2}{*}{$\begin{array}{c}\text { DFS } \\
\text { (Months) }\end{array}$} & \multirow{2}{*}{$\begin{array}{l}\text { Follow-Up } \\
\text { (Months) }\end{array}$} & \multicolumn{4}{|c|}{ MacroH2A } \\
\hline & & & & & & & & & IS & ES & IRS & \\
\hline $\mathrm{F}$ & 29 & $\mathrm{Ch}$ & 14.2 & 16.2 & Mc & pT2a & 138 & 138 & 3 & 4 & 12 & $\mathrm{H}$ \\
\hline $\mathrm{F}$ & 83 & $\mathrm{Ch} / \mathrm{CB}$ & 14.84 & 16.8 & Mc & $\mathrm{pT} 2 \mathrm{~b}$ & 123 & 123 & 0 & 0 & 0 & $\mathrm{~L}$ \\
\hline $\mathrm{F}$ & 55 & $\mathrm{Ch}$ & 9.8 & 13.9 & $\mathrm{Sc}$ & pT2a & 122 & 122 & 0 & 0 & 0 & $\mathrm{~L}$ \\
\hline $\mathrm{F}$ & 30 & $\mathrm{Ch} / \mathrm{CB}$ & 12.05 & 9.2 & Sc & pT2b & 122 & 122 & 2 & 1 & 2 & $\mathrm{~L}$ \\
\hline M & 74 & $\mathrm{Ch} / \mathrm{CB}$ & 10.04 & 16.1 & Sc & $\mathrm{pT} 2 \mathrm{~b}$ & 121 & 121 & 3 & 4 & 12 & $\mathrm{H}$ \\
\hline M & 64 & $\mathrm{Ch}$ & 7.7 & 11.5 & Sc & pT1a & 112 & 112 & 3 & 4 & 12 & $\mathrm{H}$ \\
\hline $\mathrm{F}$ & 36 & $\mathrm{Ch}$ & 5.81 & 12.7 & Sc & pT1a & 109 & 109 & 3 & 1 & 3 & $\mathrm{~L}$ \\
\hline $\mathrm{F}$ & 59 & $\mathrm{Ch}$ & 8.4 & 16.7 & Mc & pT2a & 108 & 108 & 2 & 2 & 4 & $\mathrm{~L}$ \\
\hline M & 36 & $\mathrm{Ch}$ & 6.47 & 9.8 & Mc & pT1a & 108 & 108 & 0 & 0 & 0 & $\mathrm{~L}$ \\
\hline M & 84 & $\mathrm{Ch} / \mathrm{CB}$ & 11.9 & 14.8 & Mc & pT2b & 106 & 106 & 0 & 0 & 0 & $\mathrm{~L}$ \\
\hline $\mathrm{F}$ & 67 & Ch & 10.42 & 13.02 & Mc & pT3a & 105 & 105 & 0 & 0 & 0 & $\mathrm{~L}$ \\
\hline M & 73 & $\mathrm{Ch}$ & 9.7 & 11.3 & Mc & $\mathrm{pT} 2 \mathrm{a}$ & 102 & 102 & 0 & 0 & 0 & $\mathrm{~L}$ \\
\hline $\mathrm{F}$ & 45 & $\mathrm{Ch}$ & 13.7 & 10.2 & Mc & pT2a & 96 & 96 & 0 & 0 & 0 & $\mathrm{~L}$ \\
\hline M & 58 & $\mathrm{Ch}$ & 13.1 & 14.3 & Mc & pT2a & 96 & 96 & 2 & 1 & 2 & $\mathrm{~L}$ \\
\hline M & 63 & Ch & 3.3 & 11.7 & Sc & pT2a & 85 & 85 & 2 & 3 & 6 & $\mathrm{~L}$ \\
\hline M & 54 & $\mathrm{Ch}$ & 6.32 & 10 & Sc & pT2a & 83 & 83 & 3 & 4 & 12 & $\mathrm{H}$ \\
\hline $\mathrm{F}$ & 84 & $\mathrm{Ch}$ & 11.7 & 17.4 & Mc & pT3a & 78 & 78 & 3 & 4 & 12 & $\mathrm{H}$ \\
\hline M & 73 & $\mathrm{Ch}$ & 9.24 & 17.7 & Ec & pT2a & 72 & 72 & 2 & 1 & 2 & $\mathrm{~L}$ \\
\hline M & 83 & $\mathrm{Ch}$ & 10.62 & 9.4 & Ec & pT3a & 72 & 72 & 3 & 4 & 12 & $\mathrm{H}$ \\
\hline $\mathrm{F}$ & 71 & $\mathrm{Ch}$ & 3.68 & 6.4 & Ec & pT1a & 71 & 71 & 0 & 0 & 0 & $\mathrm{~L}$ \\
\hline M & 55 & $\mathrm{Ch} / \mathrm{CB}$ & 7.5 & 8.9 & Ec & $\mathrm{pT} 2 \mathrm{~b}$ & 61 & 61 & 3 & 4 & 12 & $\mathrm{H}$ \\
\hline M & 52 & $\mathrm{Ch}$ & 9.2 & 12.1 & Sc & pT2b & 60 & 60 & 3 & 4 & 12 & $\mathrm{H}$ \\
\hline M & 46 & $\mathrm{Ch}$ & 8.76 & 11.3 & Sc & $\mathrm{pT} 2 \mathrm{a}$ & 54 & 54 & 0 & 0 & 0 & $\mathrm{~L}$ \\
\hline $\mathrm{F}$ & 76 & $\mathrm{Ch}$ & 8.02 & 10.7 & Mc & pT1a & 48 & 48 & 3 & 2 & 6 & $\mathrm{~L}$ \\
\hline $\mathrm{F}$ & 63 & $\mathrm{Ch}$ & 10.3 & 13.7 & Mc & pT2a & 42 & 42 & 0 & 0 & 0 & $\mathrm{~L}$ \\
\hline $\mathrm{F}$ & 41 & $\mathrm{Ch}$ & 5.85 & 10.3 & Mc & pT1a & 42 & 42 & 0 & 0 & 0 & $\mathrm{~L}$ \\
\hline $\mathrm{F}$ & 55 & $\mathrm{Ch}$ & 3.2 & 7.6 & Mc & pT2a & 24 & 24 & 2 & 4 & 8 & $\mathrm{~L}$ \\
\hline $\mathrm{F}$ & 74 & $\mathrm{Ch}$ & 8.6 & 10.2 & Mc & pT4b & 24 & 24 & 2 & 1 & 2 & $\mathrm{~L}$ \\
\hline M & 68 & $\mathrm{Ch} / \mathrm{CB}$ & 10.1 & 10.1 & Ec & pT1b & 24 & 24 & 0 & 0 & 0 & $\mathrm{~L}$ \\
\hline M & 74 & $\mathrm{Ch} / \mathrm{CB}$ & 14.45 & 17.5 & Ec & pT4b & 18 & 18 & 2 & 1 & 2 & $\mathrm{~L}$ \\
\hline M & 70 & $\mathrm{Ch} / \mathrm{CB}$ & 16.27 & 20.8 & Sc & pT4b & 12 & 12 & 0 & 0 & 0 & $\mathrm{~L}$ \\
\hline M & 66 & $\mathrm{Ch}$ & 9.2 & 14.1 & Mc & pT3a & 12 & 12 & 1 & 1 & 1 & $\mathrm{~L}$ \\
\hline
\end{tabular}

Abbreviations: DFS, disease-free survival; Ch, choroid; CB, ciliary body; Mc, mixed cell; Sc, spindle cell; Ec, epithelioid cell. 
Table 2. Demographics, tumor parameters, disease-free time, follow-up, and macroH2A expression in primary UMs with metastasis $(n=23)$.

\begin{tabular}{|c|c|c|c|c|c|c|c|c|c|c|c|c|}
\hline \multirow{2}{*}{ Sex } & \multirow{2}{*}{$\begin{array}{c}\text { Age } \\
\text { (years) }\end{array}$} & \multirow{2}{*}{ Location } & \multirow{2}{*}{$\begin{array}{l}\text { Thickness } \\
\text { (mm) }\end{array}$} & \multirow{2}{*}{$\begin{array}{l}\text { Largest } \\
\text { Diameter } \\
(\mathrm{mm})\end{array}$} & \multirow{2}{*}{$\begin{array}{l}\text { Cell } \\
\text { Type }\end{array}$} & \multirow{2}{*}{$\begin{array}{c}\text { Pathological } \\
\text { T Stage }\end{array}$} & \multirow[t]{2}{*}{$\begin{array}{c}\text { DFS } \\
\text { (Months) }\end{array}$} & \multirow{2}{*}{$\begin{array}{l}\text { Follow-Up } \\
\text { (Months) }\end{array}$} & \multicolumn{4}{|c|}{ MacroH2A } \\
\hline & & & & & & & & & IS & ES & IRS & \\
\hline $\mathrm{F}$ & 58 & $\mathrm{Ch}$ & 6.04 & 17.8 & Mc & pT2a & 63 & $64(†)$ & 3 & 3 & 9 & $\mathrm{~L}$ \\
\hline M & 69 & $\mathrm{Ch}$ & 7.21 & 15.8 & Mc & pT2a & 54 & $81(\dagger)$ & 3 & 4 & 12 & $\mathrm{H}$ \\
\hline $\mathrm{F}$ & 75 & $\mathrm{Ch} / \mathrm{CB}$ & 15.5 & 15.3 & Mc & pT3b & 44 & $62(t)$ & 3 & 4 & 12 & $\mathrm{H}$ \\
\hline $\mathrm{F}$ & 50 & $\mathrm{Ch}$ & 7.36 & 15.6 & Ec & pT2a & 41 & 81 & 3 & 4 & 12 & $\mathrm{H}$ \\
\hline M & 62 & $\mathrm{Ch}$ & 13.68 & 16 & Mc & pT3a & 38 & $51(†)$ & 3 & 4 & 12 & $\mathrm{H}$ \\
\hline $\mathrm{F}$ & 51 & $\mathrm{Ch} / \mathrm{CB}$ & 11.4 & 18.5 & $\mathrm{Mc}$ & pT3b & 38 & 61 & 3 & 4 & 12 & $\mathrm{H}$ \\
\hline $\mathrm{M}$ & 71 & $\mathrm{Ch}$ & 13.14 & 17.1 & Ec & pT3a & 33 & $34(+)$ & 3 & 4 & 12 & $\mathrm{H}$ \\
\hline M & 76 & $\mathrm{Ch} / \mathrm{CB}$ & 11.6 & 6.5 & $\mathrm{Mc}$ & pT1a & 31 & 39 & 0 & 0 & 0 & $\mathrm{~L}$ \\
\hline M & 72 & $\mathrm{Ch}$ & 10.3 & 15.4 & Mc & pT3b & 27 & $35(†)$ & 3 & 4 & 12 & $\mathrm{H}$ \\
\hline $\mathrm{F}$ & 85 & $\mathrm{Ch} / \mathrm{CB}$ & 7.3 & 14.7 & Sc & pT2d (EE) & 26 & $49(\dagger)$ & 3 & 4 & 12 & $\mathrm{H}$ \\
\hline M & 73 & $\mathrm{Ch}$ & 5.73 & 11.7 & $\mathrm{Ec}$ & pT2a & 26 & $42(\dagger)$ & 3 & 4 & 12 & $\mathrm{H}$ \\
\hline $\mathrm{F}$ & 51 & $\mathrm{Ch}$ & 9.42 & 19 & Mc & pT3a & 25 & 39 & 1 & 1 & 1 & $\mathrm{~L}$ \\
\hline F & 74 & $\mathrm{Ch}$ & 5.7 & 12.1 & Sc & pT2a & 24 & $37(†)$ & 3 & 4 & 12 & $\mathrm{H}$ \\
\hline $\mathrm{F}$ & 67 & $\mathrm{Ch}$ & 3.49 & 20 & Mc & pT4a & 24 & $31(+)$ & 3 & 4 & 12 & $\mathrm{H}$ \\
\hline M & 74 & $\mathrm{Ch}$ & 11.35 & 10.5 & Ec & pT3a & 19 & 47 & 3 & 4 & 12 & $\mathrm{H}$ \\
\hline M & 82 & $\mathrm{Ch}$ & 9.7 & 11 & Ec & pT2a & 19 & 42 & 3 & 4 & 12 & $\mathrm{H}$ \\
\hline $\mathrm{F}$ & 72 & $\mathrm{Ch}$ & 6.7 & 15.2 & Ec & pT2a & 14 & $28(\dagger)$ & 3 & 4 & 12 & $\mathrm{H}$ \\
\hline $\mathrm{M}$ & 76 & $\mathrm{Ch}$ & 13.7 & 17.1 & $\mathrm{Mc}$ & pT2a & 14 & 70 & 3 & 4 & 12 & $\mathrm{H}$ \\
\hline $\mathrm{M}$ & 79 & $\mathrm{Ch}$ & 13.91 & 16.1 & Ec & pT3b & 13 & 38 & 3 & 4 & 12 & $\mathrm{H}$ \\
\hline $\mathrm{F}$ & 66 & $\mathrm{Ch} / \mathrm{CB}$ & 8.95 & 12.5 & Mc & pT2b & 12 & $37(†)$ & 3 & 4 & 12 & $\mathrm{H}$ \\
\hline F & 60 & $\mathrm{Ch}$ & 8.25 & 16.5 & Ec & pT2a & 11 & $37(\dagger)$ & 3 & 4 & 12 & $\mathrm{H}$ \\
\hline $\mathrm{F}$ & 57 & $\mathrm{Ch} / \mathrm{CB}$ & 13.6 & 19 & Ec & pT2b & 6 & 55 & 3 & 4 & 12 & $\mathrm{H}$ \\
\hline M & 72 & $\mathrm{Ch} / \mathrm{CB}$ & 13.3 & 15.4 & $\mathrm{Mc}$ & pT3b & 0 & 51 & 3 & 4 & 12 & $\mathrm{H}$ \\
\hline
\end{tabular}

Abbreviations: DFS, disease-free survival; Ch, choroid; CB, ciliary body; Mc, mixed cell; Sc, spindle cell; Ec, epithelioid cell; EE, extrascleral extension; $(\dagger)$ death.

The size and site of tumor onset were studied by ophthalmoscopy and A and B scan ultrasonography, while the study of metastases was performed by physical examination, hepatic ultrasound, and computerized tomography. The median follow-up period was 60 months (range 8-138 months). Forty melanomas were localized only in the choroid, while 15 involved both the choroid and the ciliary body: only in one case was an extrascleral extension found. As concerns histotypes, 15 cases were classified as epithelioid cells and 12 as spindle cells, and 28 cases were diagnosed as mixed type.

Based on the eighth TNM classification, 23 metastatic UMs were distributed as follows: pT1a ( 1 case, $4.3 \%)$, pT2a ( 9 cases, $39.1 \%)$, pT2b ( 2 cases, $8.7 \%)$, pT2d ( 1 case, $4.3 \%)$, pT3a ( 4 cases, $17.4 \%)$, pT3b (5 cases, $21.7 \%$ ) and pT4a ( 1 case, $4.3 \%)$. TNM staging in 32 patients with metastatic UMs included pT1a ( 6 cases, $18.7 \%)$, pT1b ( 1 case, 3.1\%), pT2a (12 cases, 37.5\%), pT2b (6 cases, 18.7\%), pT3a ( 4 cases, $12.5 \%$ ), and pT4b ( 3 cases, $9.4 \%)$. We also tested mH2A in two cases of metastasis from uveal melanoma.

The cases were collected from the files of the Anatomic Pathology Department of Medical, Surgical, and Advanced Technologies, Gian Filippo Ingrassia, University of Catania. Some cases were excluded from the study for the following reasons: (1) if it was not possible to obtain sections from paraffin blocks for immunohistochemical staining, (2) the absence of representative tumor tissue, (3) the presence of exclusively necrotic material, and (4) preoperatively treated UMs.

Five sections were cut from each paraffin block. Briefly, the deparaffinized slides were pretreated with $10 \mathrm{mg} / \mathrm{mL}$ of ovalbumin in phosphate-buffered saline (PBS) followed by $0.2 \%$ biotin + in PBS, each for $15 \mathrm{~min}$ at room temperature, and they were rinsed for $20 \mathrm{~min}$ with PBS (Bio-Optica, Milan, Italy) in order to reduce the usually seen nonspecific immunoreactivity due to endogenous biotin. Microwave pretreatment was performed to unmask antigenic sites. Then the slides were incubated overnight at $4{ }^{\circ} \mathrm{C}$ with rabbit polyclonal anti-macroH2A.1 antibody (ab37264; Abcam, Cambridge, UK) diluted 1:200 in PBS (Sigma, Milan, Italy). Sections were counterstained with hematoxylin, dehydrated, mounted (Zymed Laboratories, San Francisco, CA, USA), and observed with a light microscope (Carl Zeiss, Oberkochen, Germany). 
The immunohistochemical expression of mH2A.1 was evaluated as positive if brown chromogen was observed in the nucleus. Normal skin was tested as a positive control, while the negative control was obtained through omission of the primary antibody.

Immunoreaction intensity and the percentage of stained cells were evaluated by light microscopy. Four levels (0-3) of the intensity of staining (IS) were identified: no evidence of immunoreactivity $=0$, mild immunoreactivity $=1$, intermediate immunoreactivity $=2$, and intense immunoreactivity $=3$, as described previously [9]. The extent score (ES), understood as the proportion of mH2A.1 immunopositive cells, included five levels: $<5 \%(0), 5 \%-30 \%(+), 31 \%-50 \%(++), 51 \%-75 \%(+++)$, and $>75 \%(++++)$. Counting was performed at $200 \times$ magnification. The intensity reactivity score (IRS) was obtained by multiplication of the intensity of staining (IS) and the percentage of positive cells: when the IRS was $\leq 6, \mathrm{mH} 2 \mathrm{~A} .1$ expression was considered to be "low" (L-IRS), while an IRS $>6$ was considered to be "high" expression (H-IRS).

The evaluation of immunohistochemical expression of mH2A was performed separately by three specialists in anatomic pathology (R.C., L.P., and L.S.), who were blind to the patient's identity, clinical data, and group identification.

\subsection{Statistical Analysis}

We compared the rate of high and low levels of mH2A.1 expression in melanoma of patients with and without metastasis using a chi-square test. The agreement among observations was assessed by Cohen's kappa coefficient.

We performed a univariate analysis based on a Cox proportional hazards regression model to test factors related to time free from metastasis. The parameters investigated were gender, age, melanoma location (choroid or ciliary body), temporal or nasal location, cell type (epithelioid, spindle cells, or mixed), echographic parameters (height, greatest diameter), and mH2A.1 expression (low and high).

Factors with a $p$-value $<0.15$ were included in the multivariate analysis.

We performed a survival analysis based on high and low mH2A.1 expression using the Kaplan-Meier test: survival rates were compared using a log-rank (Mantel-Cox) test, and $p$-values lower than 0.05 were considered to be statistically significant.

\section{Results}

\subsection{Clinicopathological Characteristics of UMs}

Comparing patients without metastasis and with metastasis, no significant difference was observed in median age, site (choroid or choroid/ciliary body), thickness, cell type, extrascleral extension, and pTNM: patients with metastatic melanoma showed a greater median largest diameter (15.6 mm vs $11.9 \mathrm{~mm}, p=0.007$ ) and higher median mH2A.1 expression (12 vs $2, p<0.001)$. They also had lower median disease-free survival ( 25 months vs 81 months, $p<0.001$ ) (Table 3 ). 
Table 3. Medians (range) of demographics, tumor parameters, disease-free time, follow-up, and macroH2A expression in primary UMs without and with systemic metastasis.

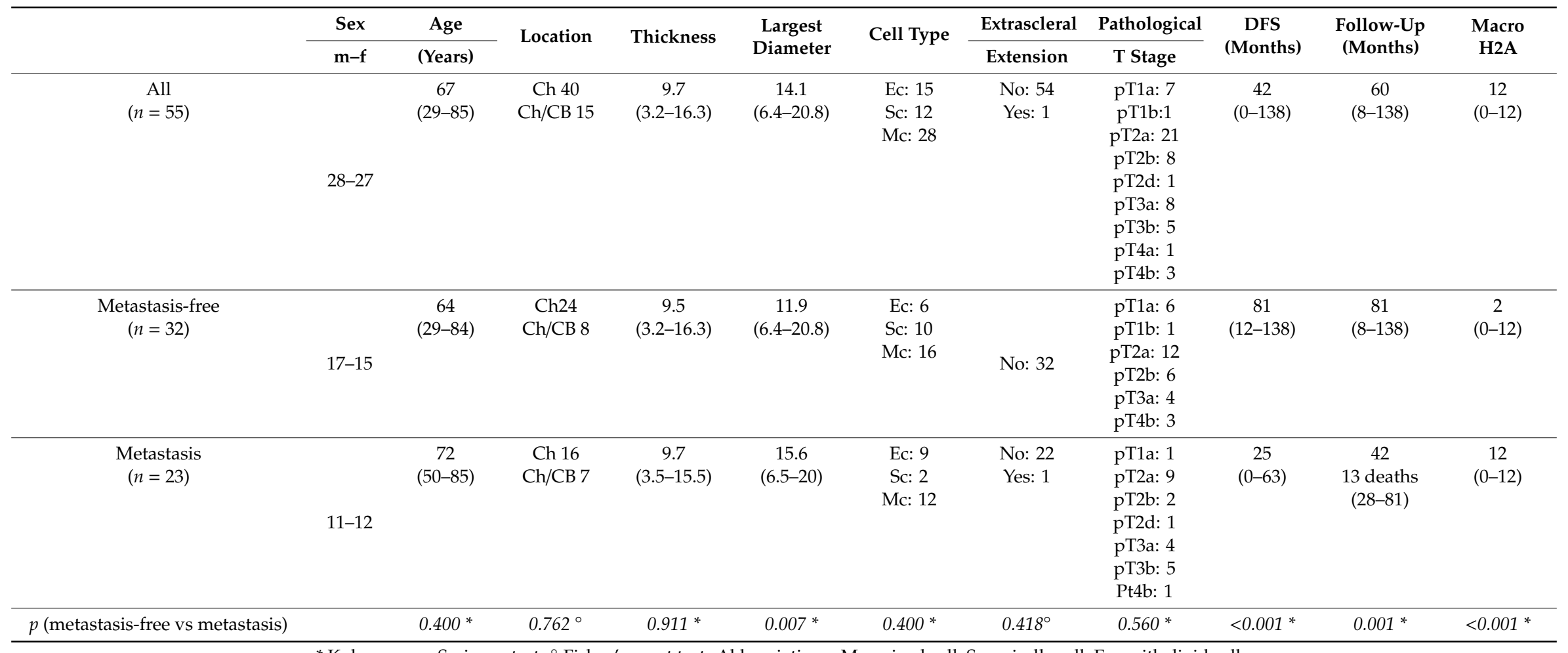

${ }^{*}$ Kolmogorov-Smirnov test. ${ }^{\circ}$ Fisher's exact test. Abbreviations: Mc, mixed cell; Sc, spindle cell; Ec, epithelioid cell. 


\section{2. $m$ H2A.1 Expression and Clinicopathological Features in UMs}

Immunohistochemistry showed only mH2A.1 nuclear staining: no immunohistochemical expression of mH2A.1 was observed in non-neoplastic ocular tissue. Interobserver agreement was excellent (kappa $=0.943)$.

Considering the whole group $(n=55)$, the median mH2A.1 value was 12 : H-IRS was observed in 28 (50.9\%) melanomas and L-IRS in 27 (49.1\%).

In 32 nonmetastatic primary UMs, mH2A.1 IS was intense/intermediate in 18 cases (56.3\%) and mild in only one case (3.1\%), while in $13(40.6 \%)$ cases no immunoreactivity was observed (Figure 1). ES was $>50 \%$ in 10 cases (31.3\%) and 5\%-30\% in 9 cases (28.1\%). Only 8/32 cases (25\%) showed H-IRS, while 24 cases $(75 \%)$ showed L-IRS (Table 1) (Fisher's exact test, $p<0.001$, Table 4 ).

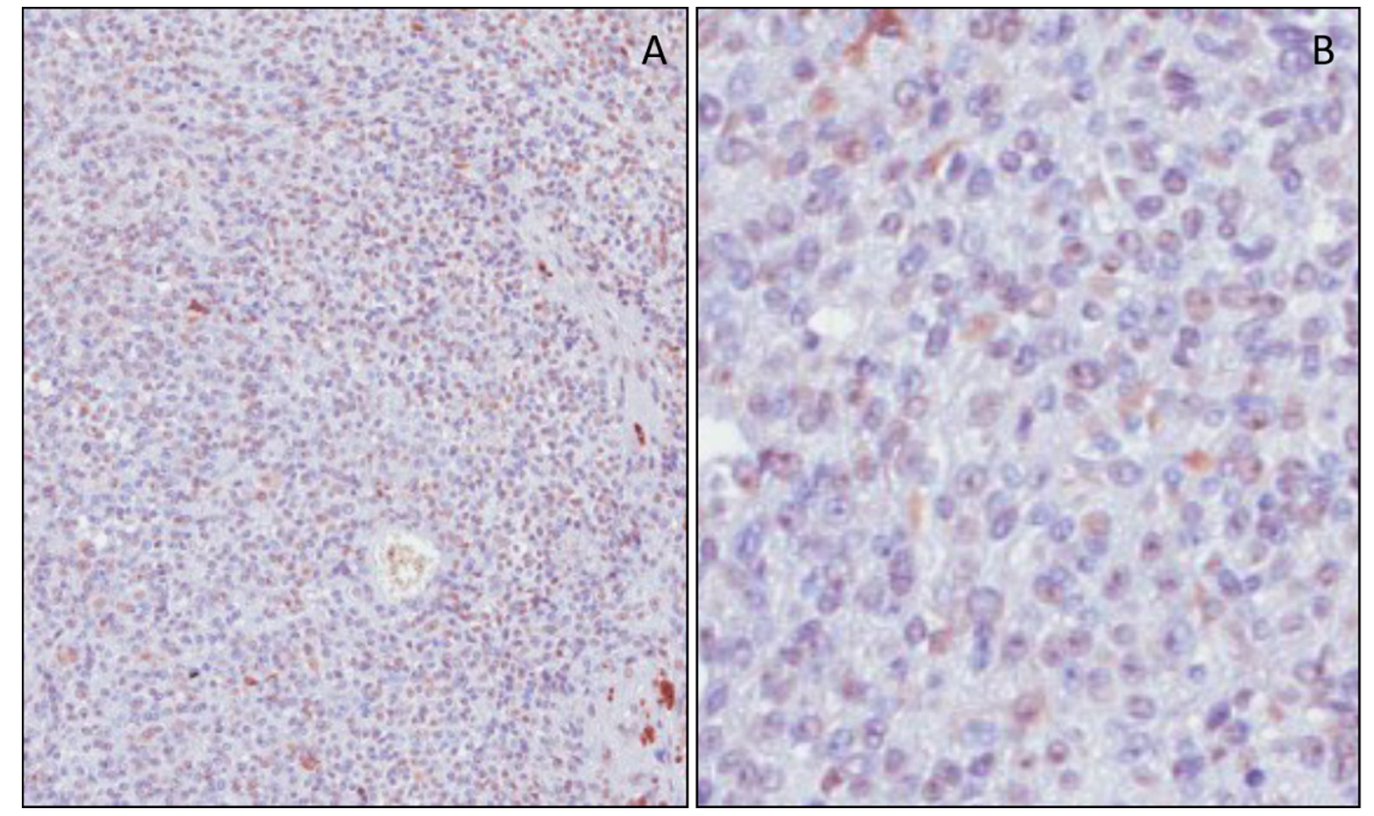

Figure 1. Immunohistochemical expression of mH2A.1 in nonmetastatic uveal melanomas. Melanoma cells showed weak staining for macroH2A.1 (low magnification in (A) and high magnification in (B)).

Table 4. Number of UMs (with and without metastasis) with low and high macroH2A.

\begin{tabular}{ccc}
\hline mH2A & Metastasis $(\boldsymbol{n}=\mathbf{2 3})$ & Metastasis-Free $(\boldsymbol{n}=\mathbf{3 2})$ \\
\hline Low & $3(13 \%) *$ & $24(75 \%)$ \\
High & $20(87 \%)$ & $8(25 \%)$ \\
\hline
\end{tabular}

Abbreviations: mH2A, macroH2A. $p$ (Fisher's exact test). ${ }^{*} p<0.0001$.

In 23 metastatic primary UMs, mH2A.1 IS was intense/intermediate in 21 cases (91.4\%) and mild in 1 case $(4.3 \%)$. Only 1 case (4.3\%) showed an absence of immunoreactivity (Figure 2 ). ES was $>75 \%$ in 20 cases $(87 \%), 50 \%-75 \%$ in 1 case $(4.3 \%)$, and $5 \%-30 \%$ in 1 case $(4.3 \%)$. Here, $20 / 23$ cases $(87 \%)$ showed H-IRS, while only 3 cases (13\%) had L-IRS (Table 2) (Fisher's exact test, $p<0.001$, Table 4). 


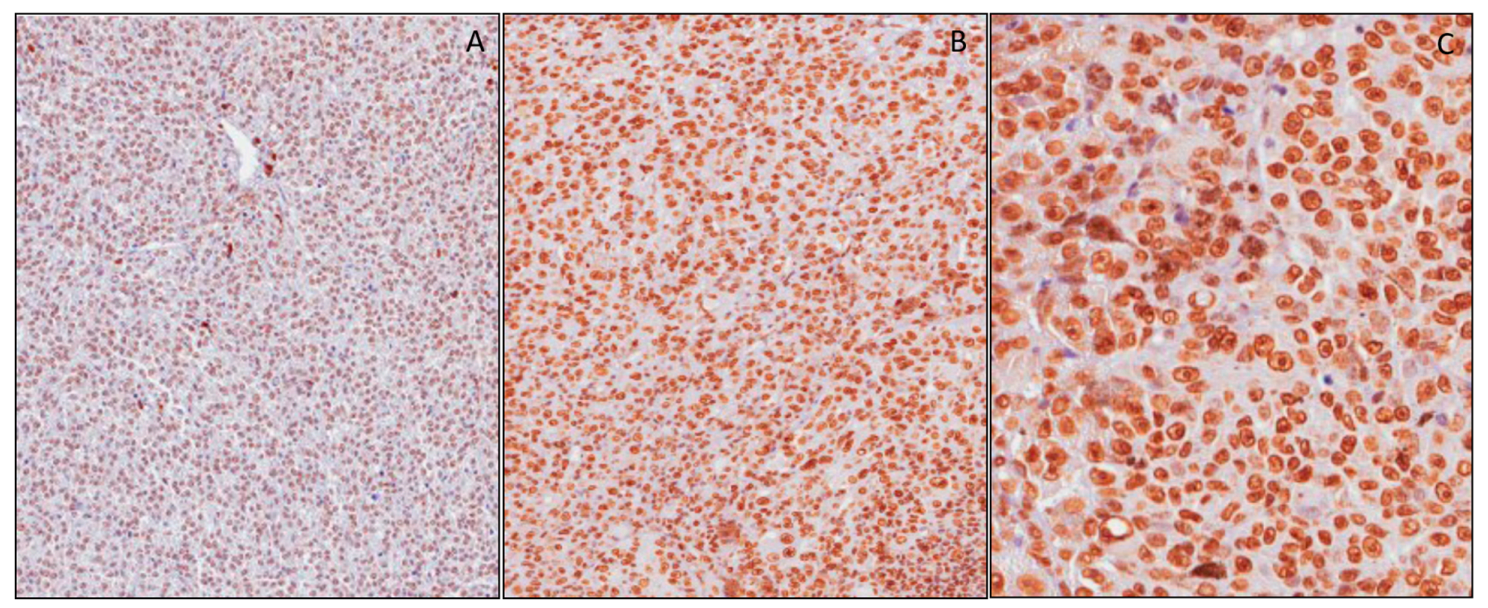

Figure 2. Immunohistochemical expression of mH2A.1 in metastatic uveal melanomas. Tumor cells revealed moderate (IS 2) immunoreactivity in (A). (B) and (C) show strong staining (IS 3), respectively, at low and high magnifications.

In two cases of metastasis from uveal melanoma, mH2A.1 showed diffuse and intense immunoreactivity with H-IRS (Figure 3).

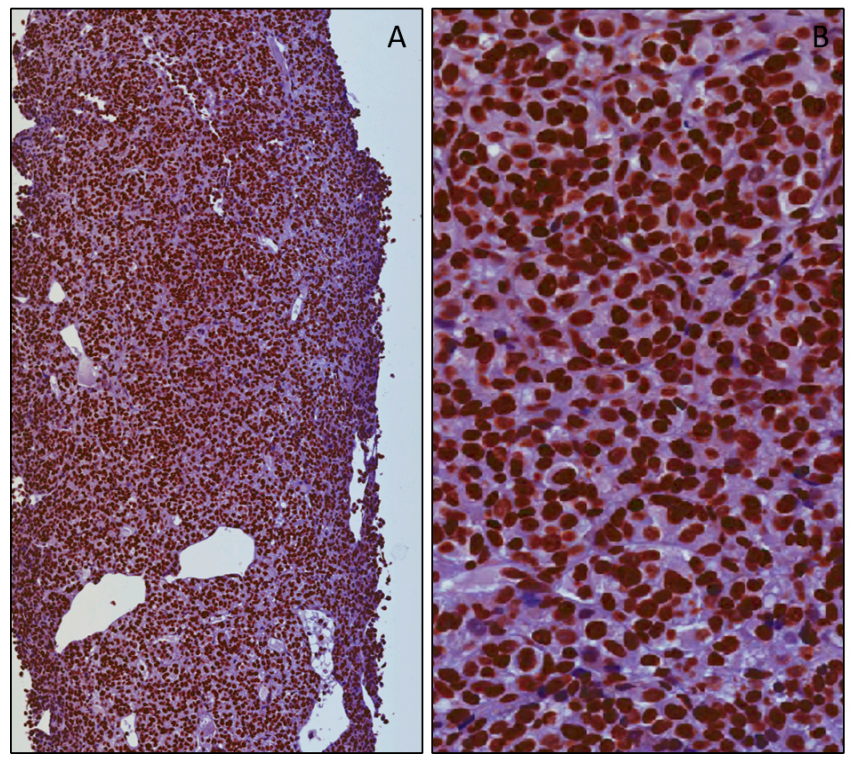

Figure 3. Immunohistochemical expression of mH2A.1 in metastases from uveal melanomas. Metastatic cells revealed diffuse (ES 4) and strong (IS 4) immunoreactivity, respectively, at low (A) and high magnifications (B).

Univariate analysis based on a Cox proportional hazards regression model revealed that factors related to the presence of metastasis were age $(p=0.053)$, greater tumor size $(p=0.009), \mathrm{pT}$ (pathological Tumor) stage $(p=0.016)$, the epithelioid variant $(p=0.011)$, and mH2A.1 expression $(p<0.001)$. Factors significantly related to the presence of metastasis in the multivariate analysis were mH2A.1 expression $(p=0.002)$, greater tumor size $(p=0.026)$, and the epithelioid variant $(p=0.019)$.

Here, mH2A.1 expression was not related to histological type (Spearman's rho, $p=0.173$ ). A Kaplan-Meier survival analysis showed that the estimated survival times free from metastasis were greater in patients with low mH2A.1 expression in UMs: mean values (SE (Standard error), with 95\% CI (confidential interval)) were 110.3 (6.80) (CI: 97.0 to 123.7) in patients with low mH2A.1 expression and 56.7 (10.0) (CI: 37.2 to 76.2) in patients with high mH2A.1 expression $(p<0.001$, log-rank (Mantel-Cox) test, Figure 4). 


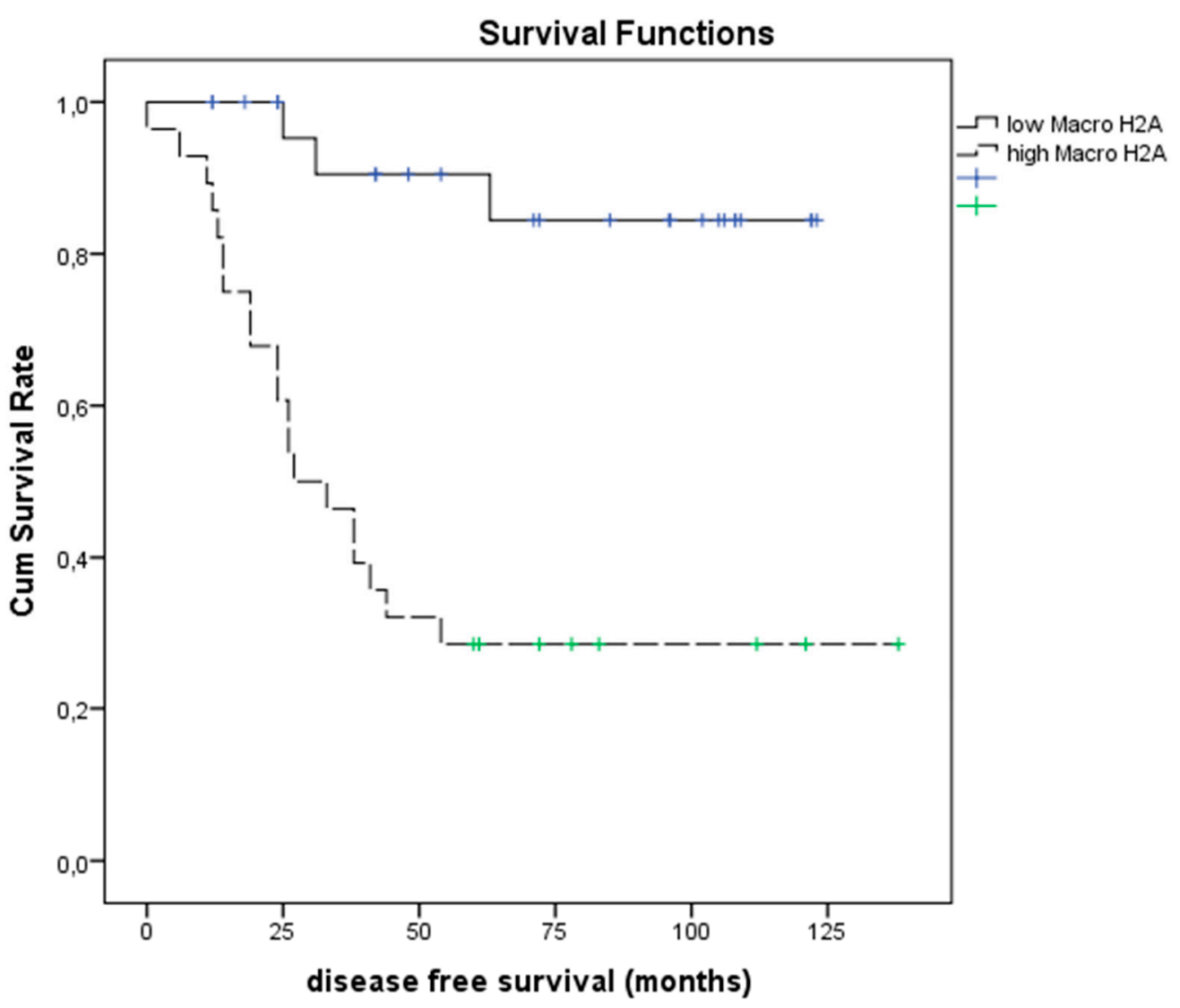

Figure 4. Kaplan-Meier test. Survival analyses (Kaplan-Meier) in patients with UMs with low and high macroH2A expression ( $p<0.001$, log-rank (Mantel-Cox) test).

\section{Discussion}

$\mathrm{UM}$ is an ambiguous neoplasia because regardless of the histological subtype and initial stage, it can metastasize to the liver, even after 10-15 years [4]. From the diagnosis of hepatic metastasis, death usually occurs within one year, and there is a lack of effective treatment. Asymptomatic patients with an early detection of metastasis seem to have an apparent benefit, while adjuvant therapies and screening do not seem to provide a significant survival benefit $[10,11]$. The prognosis of UM depends on multiple clinical data points: adult/senile age, male gender, large tumor, tumor thickness, ciliary body site, eye or skin melanocytosis, extraocular involvement at presentation, and advanced stage. Histopathological parameters (epithelioid cell variant, numerous mitoses, microvascular proliferation, microvascular loops and patterns, intratumoral lymphocytes, intratumoral macrophages, strong expression of IGF-1R (insulin-like growth factor-1 receptor) and HLA (Human Leucocyte Antigen) class I and II), cytogenetic factors (monosomy 3, chromosome 8q-gain or 8p-loss, chromosome 1p-loss, chromosome 6q-loss), and transcriptomic factors (gene expression profile class 2 ) [10,11] play a role as prognostic factors.

However, much remains to be understood to limit the onset of metastases or to identify effective treatments in metastatic patients.

Indeed, research is being focused on factors that can identify tumors with aggressive behavior and find new therapeutic targets. Our research group has tried to determine the unusual behavior of UM by testing different molecules and factors such as ADAM10, RKIP, pRKIP, ABCB5, and SPANX-C [9,12,13].

Recent studies have reported the inactivation of somatic mutations in gene-encoding BRCA-1-associated protein 1 (BAP1) in about $84 \%$ of metastasizing UMs [14]: the high frequency of BAP1 mutations in metastatic UMs encouraged us to search for new therapeutic strategies with the target molecule BAP1, which have deubiquitinase activity on histone H2A [15,16]. In different tumors, 
including skin melanoma, mH2A and its variants, which are widely distributed along chromatin [17-19], have been regarded as a potential prognostic marker [20,21].

Previously, Kapoor et al. [6] reported that the histone variant mH2A suppressed the tumor progression of malignant cutaneous melanoma and that the loss of mH2A isoforms was positively correlated with increasing malignant phenotypes of cutaneous melanoma cells in culture and human tissue samples. In addition, they suggested that the tumor-promoting function of $\mathrm{mH} 2 \mathrm{~A}$ loss was mediated, at least in part, through direct transcriptional upregulation of CDK8.

Lei et al. [7] showed that high expression of mH2A suppressed melanoma cell progression and arrested cells in the G2/M phase. Thus, we hypothesized that an alteration in $\mathrm{mH} 2 \mathrm{~A}$ expression could contribute to a change in the phenotype of UMs, promoting tumor progression. Therefore, $\mathrm{mH} 2 \mathrm{~A}$ would be the basis for this mechanism, whose final effect would be stabilizing the cell cycle, which is frequently observed in malignant neoplasms, in particular in tumor lesions with a low proliferative index. Furthermore, the arrest of the cell cycle would make the cell not very sensitive to chemotherapy, suggesting a further predictive role in the response to therapy. In the present study, we showed that an elevated increased expression of $\mathrm{mH} 2 \mathrm{~A}$ correlated with tumor progression: indeed, metastasizing UMs showed the highest expression of mH2A. This assay might prove that a high expression of histone protein correlates with an advanced tumor phase.

In this study, we saw that mH2A overexpression was a prognostic factor for the risk of metastasis. In our series of UMs, $\mathrm{mH} 2 \mathrm{~A}$ was strongly expressed in more than $75 \%$ of neoplastic cells, with a median IRS value of 12. In patients with H-IRS, we observed an increased incidence of metastasis after surgical treatment. These data were also confirmed by the high expression of $\mathrm{mH} 2 \mathrm{~A}$ in metastases, although this was limited to only two cases. Conversely, the cases with L-IRS showed a decreased risk of metastasis. In addition, a Kaplan-Meier survival analysis showed that patients with UMs and H-IRS had lower metastasis-free survival times.

In conclusion, our results highlight the important role played by $\mathrm{mH} 2 \mathrm{~A}$ in UM progression. The immunohistochemical expression of $\mathrm{mH} 2 \mathrm{~A}$ could be a suitable and easily detectable marker in the primary tumor, predicting the risk of UM metastasis and thus directing strategies for monitoring and therapy.

Author Contributions: Conceptualization, L.S. and R.C.; data curation, G.B., S.P., A.L., A.R., M.R., M.V., G.L.V., and R.C.; methodology, L.S., L.P., and R.C.; resources, R.C.; writing—original draft, L.S.; writing—review and editing, L.S. and R.C.

Funding: The project was funded by the intradepartmental research plan 2016/2018 of the Department of Medical, Surgical, and Advanced Technologies, University of Catania (funding number 5C722012114, 2018) and by the European Social Fund and European Regional Development Fund-Project MAGNET (No. CZ.02.1.01/0.0/0.0/15_003/0000492).

Acknowledgments: The authors would like to thank the Department "GF Ingrassia" of the University of Catania for financial support, and the Scientific Bureau of the University of Catania for language assistance.

Conflicts of Interest: The authors declare no conflicts of interest.

\section{References}

1. Pukrushpan, P.; Tulvatana, W.; Pittayapongpat, R. Congenitaluvealmalignantmelanoma. J. AAPOS 2014, 18, 199-201. [CrossRef] [PubMed]

2. Spagnolo, F.; Caltabiano, G.; Queirolo, P. Uveal melanoma. Cancer Treat. Rev. 2012, 38, 549-553. [CrossRef] [PubMed]

3. McLean, I.W.; Foster, W.D.; Zimmerman, L.E.; Gamel, J.W. Modifications of Callender's classi fication of uveal melanoma at the Armed Forces Institute of Pathology. Am. J. Ophthalmol. 1983, 96, 502-509. [CrossRef]

4. Willson, J.K.; Albert, D.M.; Moy, C.S. Collaborative Ocular Melanoma Study Group, Assessment of metastaticdisease status atdeath in 435 patients with large choroidal melanoma in the Collaborative Ocular Melanoma Study (COMS): COMS report no. 15. Arch. Ophthalmol. 2001, 119, 670-676. [CrossRef]

5. Cantariño, N.; Douet, J.; Buschbeck, M. MacroH2A-An epigeneticregulator of cancer. Cancer Lett. 2013, 336, 247-252. [CrossRef] 
6. Kapoor, A.; Goldberg, M.S.; Cumberland, L.K.; Ratnakumar, K.; Segura, M.F.; Emanuel, P.O.; Menendez, S.; Vardabasso, C.; Leroy, G.; Vidal, C.I.; et al. The histonevariant macroH2A suppresses melanoma progressionthroughregulation of CDK8. Nature 2010, 468, 1105-1109. [CrossRef] [PubMed]

7. Lei, S.; Long, J.; Li, J. MacroH2A suppresses the proliferation of the B16 melanoma cell line. Mol. Med. Rep. 2014, 10, 1845-1850. [CrossRef]

8. Choudhary, M.M.; Triozzi, P.L.; Singh, A.D. Uveal melanoma: Evidence for adjuvanttherapy. Int. Ophthalmol. Clin. 2015, 55, 45-51. [CrossRef]

9. Caltabiano, R.; Puzzo, L.; Barresi, V.; Ieni, A.; Loreto, C.; Musumeci, G.; Castrogiovanni, P.; Ragusa, M.; Foti, P.; Russo, A.; et al. ADAM 10 expression in primaryuveal melanoma asprognosticfactor for risk of metastasis. Pathol. Res. Pract. 2016, 212, 980-987. [CrossRef]

10. Augsburger, J.J.; Corrêa, Z.M.; Trichopoulos, N. Surveillancetesting for metastasis from primaryuveal melanoma and effect on patientsurvival. Am. J. Ophthalmol. 2011, 152, 5-9. [CrossRef]

11. Kaliki, S.; Shields, C.L. Uveal melanoma: Relatively rare butdeadlycancer. Eye 2017, 31, 241-257. [CrossRef] [PubMed]

12. Caltabiano, R.; Puzzo, L.; Barresi, V.; Cardile, V.; Loreto, C.; Ragusa, M.; Russo, A.; Reibaldi, M.; Longo, A. Expression of RafKinaseInhibitorProtein (RKIP) is apredictor of uveal melanoma Metastasis. Histol Histopathol. 2014, 29, 1325-1334. [CrossRef] [PubMed]

13. Salvatorelli, L.; Puzzo, L.; Russo, A.; Reibaldi, M.; Longo, A.; Ragusa, M.; Aldo, C.; Rappazzo, G.; Caltabiano, R.; Salemi, M. Immunoexpression of SPANX-C in metastaticuveal melanoma. Pathol. Res. Pract. 2019, 29, 152431. [CrossRef] [PubMed]

14. Harbour, J.W.; Onken, M.D.; Roberson, E.D.; Duan, S.; Cao, L.; Worley, L.A.; Council, M.L.; Matatall, K.L.; Helms, C.; Bowcock, A.M.; et al. Frequentmutation of BAP1 in metastasizinguvealmelanomas. Science 2010, 330, 1410-1413. [CrossRef] [PubMed]

15. Scheuermann, J.C.; de Ayala Alonso, A.G.; Oktaba, K.; Ly-Hartig, N.; McGinty, R.K.; Fraterman, S. Histone H2A deubiquitinaseactivity of the Polycomb repressive complex PR-DUB. Nature 2010, 465, $243-247$. [CrossRef] [PubMed]

16. Machida, Y.J.; Machida, Y.; Vashisht, A.A.; Wohlschlegel, J.A.; Dutta, A. The deubiquitinatingenzyme BAP1 regulatescellgrowth via interaction with HCF-1. J. Biol. Chem. 2009, 284, 34179-34188. [CrossRef] [PubMed]

17. Costanzi, C.; Pehrson, J.R. Histone macroH2A1 isconcentrated in the inactive X chromosome offemalemammals. Nature 1998, 393, 599-601. [CrossRef] [PubMed]

18. Zhang, R.; Poustovoitov, M.V.; Ye, X.; Santos, H.A.; Chen, W.; Daganzo, S.M.; Erzberger, J.P.; Dunbrack, R.L.; Adams, P.D.; Berger, J.M.; et al. Formation ofMacroH2A-containing senescence-associatedheterochromatin foci and senescencedriven by ASF1aand HIRA. Dev. Cell. 2005, 8, 19-30. [CrossRef]

19. Bernstein, E.; Muratore-Schroeder, T.L.; Diaz, R.L.; Chow, J.C.; Changolkar, L.N.; Shabanowitz, J.; Heard, E.; Pehrson, J.R.; Hunt, D.F.; Allis, C.D. A phosphorylated subpopulation of the histone variant macroH2A1 is excluded from the inactive X chromosome and enriched during mitosis. Proc. Natl. Acad. Sci. USA 2008, 105, 1533-1538. [CrossRef]

20. Lo Re, O.; Fusilli, C.; Rappa, F.; Van Haele, M.; Douet, J.; Pindjakova, J.; Pata, L.; Vinciguerra, M.; Mazza, T.; Buschbeck, M.; et al. Induction of cancercellstemness by depletion of macrohistone H2A1 in hepatocellular carcinoma. Hepatology 2018, 67, 636-650. [CrossRef]

21. Hua, S.; Kallen, C.B.; Dhar, R.; Baquero, M.T.; Mason, C.E.; Russell, B.A.; White, K.P.; Rimm, D.L.; Krausz, T.N.; Shah, P.K.; et al. Genomicanalysis of estrogencascaderevealshistonevariant H2A.Z associated with breastcancerprogression. Mol. Syst. Biol. 2008, 4, 188. [CrossRef] [PubMed]

(C) 2019 by the authors. Licensee MDPI, Basel, Switzerland. This article is an open access article distributed under the terms and conditions of the Creative Commons Attribution (CC BY) license (http://creativecommons.org/licenses/by/4.0/). 